\title{
Enzyme Replacement Therapy with Polyethylene Glycol-Adenosine Deaminase in Adenosine Deaminase Deficiency: Overview and Case Reports of Three Patients, Including Two Now Receiving Gene Therapy
}

\author{
MICHAEL S. HERSHFIELD, SARA CHAFFEE, AND RICARDO U. SORENSEN \\ Departments of Medicine and Pediatrics, Duke University Medical Center, Durham, North Carolina 27710; and \\ Department of Pediatrics, Division of Allergy and Immunology, Louisiana State University Medical Center, New \\ Orleans, Louisiana 70112
}

\begin{abstract}
During the past 6 y, 29 adenosine deaminase (ADA)-deficient patients with combined immunodeficiency have been treated with polyethylene glycol (PEG)-modified bovine ADA (PEG-ADA). We have monitored plasma ADA activity, metabolic effects of treatment, and the evolution of antibody to PEG-ADA in these patients, in collaboration with immunologists and clinicians in North America, Europe, and Australia, who have monitored immune function and clinical response to treatment. This article summarizes the current status of PEG-ADA therapy and provides recommendations for its use. Recovery of specific immune function during treatment with PEG-ADA is illustrated for three patients, who represent early, delayed, and late onset of immunodeficiency disease. Two of these patients have entered a trial of gene therapy, but continue to receive enzyme replacement. (Pediatr Res 33 (Suppl): S42-S48, 1993)
\end{abstract}

\section{Abbreviations}

ADA, adenosine deaminase

dAdo, deoxyadenosine

dATP, deoxy adenosine $5^{\prime}$-triphosphate

IVIG, intravenous immune globulin

PEG, polyethylene glycol

SCID, severe combined immunodeficiency disease

SAHase, S-adenosylhomocysteine hydrolase

In April 1986, we became involved in a clinical trial of an untested approach to enzyme replacement therapy for ADA deficiency in a gravely ill child with SCID who had unsuccessful haploidentical bone marrow transplantation and enzyme replacement by red cell transfusion (1). The new method, which involved injecting PEG-ADA, was based on the discovery that covalent attachment of PEG could prolong the circulating life and reduce the immunogenicity of proteins (2-4). The approach offered the possibility of achieving very high levels of plasma ADA activity and appeared to be feasible because, as discussed elsewhere $(5,6)$, efficient catabolism of extracellular ADA substrates can prevent their toxicity to ADA-deficient lymphoid cells.

Correspondence: Michael S. Hershfield, M.D., Box 3049, Room 418 Sands Building, Duke University Medical Center, Durham, NC 27710.

Supported by NIH Grant DK20902 (M.S.H.) and USPHS, NIH Grant RR00080 (R.U.S.), and by funds from Enzon, Inc. M.S.H. is a consultant to Enzon, Inc.
Detailed study of the initial patient and another provided information about the pharmacokinetics of PEG-ADA and suggested that weekly injections could be effective in correcting metabolic abnormalities and restoring a degree of immune function (1). An international clinical trial followed in which we monitored the biochemical and metabolic effects of PEG-ADA and the evolution of anti-ADA antibodies, in collaboration with the physicians and immunologists who cared for affected patients and evaluated their clinical status and immunologic function. Results with several patients treated with PEG-ADA for periods of less than $1 \mathrm{y}$ have been published $(1,7-9)$, and the experience with 14 patients begun on treatment through the spring of 1990 , when PEG-ADA (Adagen, Enzon, Inc., So. Plainfield, NJ) was approved by the US Food and Drug Administration, has been summarized (6). The IgG antibody response to PEG-ADA in 17 patients has been reported (10). The following is a brief summary of the current status of PEG-ADA therapy, with some new recommendations for its use, based on observations of 29 patients treated to date.

In addition to summarizing the overall experience with PEGADA, we describe the recovery of specific immune function during 1.5 to almost $4 \mathrm{y}$ of enzyme replacement in three patients, who represent examples of ADA deficiency with early, delayed, and late onset of immunodeficiency disease. Two of these patients have become the first subjects of a "gene therapy" experiment begun at the National Institutes of Health in the fall of 1990. During their participation in this experiment, both children have continued to receive PEG-ADA without interruption. In evaluating treatment with both modalities simultaneously, it is informative to review their response to enzyme replacement alone.

\section{RESULTS}

Overview of PEG-ADA Therapy. Profile of patients treated with $P E G-A D A$. Through January 1992, 29 patients had been treated with PEG-ADA. Overall, 15 patients began treatment at $<1 \mathrm{y}$, six at 1 to $2 \mathrm{y}$, and eight at 3 to $14 \mathrm{y}$ of age. However, the age distribution changed as the study progressed, reflecting the fact that most of the initial group of patients had been diagnosed before PEG-ADA was available. Thus, during the 48 mo before March 1990 (when Food and Drug Administration approval was obtained), only two of 13 patients began treatment at $<1$ y of age, compared with 13 of 16 during the ensuing 21 -mo period. At present, 18 patients have been under treatment for 16 to 71 mo (mean, $40 \mathrm{mo}$ ), the remainder from 1 to $11 \mathrm{mo}$.

None of the patients had an HLA-identical sibling. Only the 
first patient had undergone haploidentical marrow transplantation. Patients 2-4 had been treated with monthly erythrocyte transfusions, a form of enzyme replacement, $(11,12)$ for 8 to 9 $\mathrm{y}$ before switching to PEG-ADA at 9 to $12 \mathrm{y}$ of age; several other patients among the first dozen had received transfusions for variable periods of less than $2 \mathrm{y}$. Four patients were diagnosed at 3 to 8 y of age; the oldest started to receive PEG-ADA at age $14.9 \mathrm{y}$, and the other three began enzyme therapy within $6 \mathrm{mo}$ of diagnosis. Most patients were receiving IVIG at the time that enzyme replacement was begun.

Dose, route, and schedule of administration. Patients were treated by intramuscular injection of a preparation (Adagen) containing $250 \mathrm{U} / \mathrm{mL}$ of $\mathrm{ADA}$ activity, as determined by the manufacturer by using a spectrophotometric assay at $25^{\circ} \mathrm{C}(\mathrm{U}=$ $1 \mu \mathrm{mol}$ of adenosine converted to inosine per min). During the first 2 y of its use, PEG-ADA was administered once weekly, beginning at $5-10 \mathrm{U} / \mathrm{kg}$, with escalation over 2 to 3 wk to a maintenance dose of 15 or $20 \mathrm{U} / \mathrm{kg}(1,7)$. As more patients less than 1 y of age began therapy (see above), it became apparent that PEG-ADA was cleared more rapidly in younger children, particularly if growth was retarded by acute and chronic infection. Treatment of newly diagnosed patients is now initiated with twice weekly injections of $30 \mathrm{U} / \mathrm{kg}(60 \mathrm{U} / \mathrm{kg} / \mathrm{wk})$, and the dose is calculated from "ideal body weight," i.e. that of a child of the same age who is in the 50th percentile for weight (Weinberg K, unpublished data). The twice-weekly schedule is maintained for 1 to 3 mo until metabolic abnormalities are corrected, the child is clinically stable, and there is evidence of improved immune function (increasing lymphocyte count and in vitro proliferative response to mitogens). A $30-\mathrm{U} / \mathrm{kg}$, once-weekly maintenance schedule is then begun and adjusted, if necessary, according to the trough (preinjection) level of plasma ADA activity or, in some cases, immune function.

Plasma ADA activity is monitored at $37^{\circ} \mathrm{C}$ as previously reported (1). After intramuscular injection, plasma ADA activity peaks in 24 to $48 \mathrm{~h}$ and decreases to roughly half the peak level by $\mathrm{d} 7$ postinjection (half-life after the peak varies from $\sim 3$ to $>6 \mathrm{~d}$ ). Trough ADA activity fluctuates about 2-fold from week to week, but when averaged over time it is proportional to the dose of PEG-ADA (10). Plasma ADA activity in normal individuals and ADA-deficient children is negligible $(\sim 0.05-0.2 \mu \mathrm{mol} /$ $\mathrm{h} / \mathrm{mL}$ ). Initial studies indicated that the PEG-ADA dose should be adjusted to keep plasma ADA activity above $12 \mu \mathrm{mol} / \mathrm{h} / \mathrm{mL}$, which is the upper range for normal total blood (erythrocyte) ADA activity. At present, trough plasma ADA activity is maintained at $>20 \mu \mathrm{mol} / \mathrm{h} / \mathrm{mL}$ in nearly all patients on one weekly injection of PEG-ADA. In those treated twice weekly (40-60 U/ $\mathrm{kg} / \mathrm{wk}$ ), preinjection plasma ADA levels range from $\sim 40$ to 90 $\mu \mathrm{mol} / \mathrm{h} / \mathrm{mL}$; in a few cases levels have reached 120 to $150 \mu \mathrm{mol} /$ $\mathrm{h} / \mathrm{mL}$ for a few weeks without ill effect.

Antibody response to $P E G-A D A$. There have been no reports of allergic or hypersensitivity reactions to PEG-ADA. ELISAdetectable IgG antibody to bovine ADA was found in 10 of 17 patients treated for 1 to 5.5 y (10). Antibody usually appeared between the 3rd and 8th mo of treatment. Anti-ADA levels did not correlate with trough plasma ADA activity, which remained stable in eight of 10 anti-ADA-positive patients over periods from 24 to $60 \mathrm{mo}$. Enhanced enzyme clearance, mediated by antibody that directly inhibited PEG-ADA, occurred in two patients after 4 to 5 mo of treatment. In one patient, tolerance was induced by a regimen that included twice-weekly injections of PEG-ADA, high-dose IVIG for several weeks, and a 4-mo tapering course of prednisone; a once-weekly injection schedule was then resumed $(10,13)$. In the second patient, twice-weekly injections of PEG-ADA compensated for accelerated clearance. Both patients continue to receive PEG-ADA and are doing well clinically after 2.7 and 3.5 y of therapy [(9), Stiehm ER, Girault $\mathrm{D}$, unpublished data].

Because of the possibility of developing enhanced clearance due to antibody, we recommend monitoring preinjection plasma
ADA levels every other week during the first 6 to 8 mo of therapy with PEG-ADA, then monthly. Assay for anti-ADA antibodies by ELISA and by enzyme inhibition should be performed promptly if a persistent decline in enzyme level occurs. In such cases, measures should be taken to prevent or treat infection and to restore adequate enzyme levels. We are pursuing the possible use of PEG-modified human ADA for treating ADA deficiency because, as discussed elsewhere, this might reduce the likelihood of developing anti-ADA antibody and simplify the monitoring of therapy (10).

Metabolic response to PEG-ADA. Treatment with PEG-ADA largely reverses the toxic intracellular effects of dAdo [reviewed in (5)]. Total dAdo nucleotides in erythrocytes fall by $\sim 100$-fold (on average) and the activity of SAHase, which is inactivated by dAdo in ADA deficiency, increases about 10- to 20-fold into the normal range (1, 7-9). These effects are achieved during the first 2 mo of treatment and are maintained on continuing therapy.

Immune reconstitution. Improvement in lymphocyte counts and immune function follows correction of erythrocyte metabolic abnormalities within a few weeks to several months. Reappearance of a thymic shadow has been observed in some patients. The degree of immune reconstitution varies. Lymphocyte counts rise during the first 6 to $12 \mathrm{mo}$. In some patients, normal lymphocyte counts are maintained, but in others the counts fall during the second year of treatment and a degree of lymphopenia persists thereafter despite maintenance of circulating ADA levels and correction of metabolic abnormalities. About one fifth of patients show little improvement in proliferative response of blood mononuclear cells to mitogens. The remainder develop responses ranging from $\sim 30 \%$ to $>90 \%$ of normal; about 40 to $50 \%$ of patients have also developed proliferative responses to antigens. However, lymphocyte responses to both mitogens and antigens fluctuate over time, in some patients more than in others.

Serum Ig rise with enzyme replacement, and thus far about half the patients have discontinued IVIG, in some cases by 3 to 6 mo of beginning PEG-ADA treatment. Normal antibody titers after immunization have been demonstrated in these patients. Criteria for stopping IVIG are not uniform, but in general the decision has been based on normalization of CD4 T-cell counts and in vitro $\mathrm{T}$-cell function. The presence of chronic pulmonary insufficiency in some older patients has been considered an indication for continuing monthly IVIG prophylaxis. A useful way of evaluating humoral immunity in some patients receiving IVIG has been the response to immunization with the bacteriophage $\phi \mathrm{X} 174$, inasmuch as IVIG preparations do not contain antibodies to this phage. A normal response to $\phi \mathrm{X} 174$, including amplification with rechallenge and IgM-to-IgG class switching, was observed in three of four PEG-ADA-treated patients (two of the responders on PEG-ADA had abnormal responses while receiving transfusion therapy before starting PEG-ADA) (14).

Immune dysregulation may occur during the initial period of therapy when immune reconstitution is beginning. Two patients have developed autoimmune phenomena (thrombocytopenia in one case, hemolytic anemia in another) following viral infections during the first 2 to 3 mo of treatment [(15) and Junker A, unpublished data]. Autoimmune thrombocytopenia resolved with high-dose IVIG therapy and has not recurred in over $3 \mathrm{y}$. The autoimmune hemolytic anemia did not respond to aggressive immunosuppression (see below).

Clinical status. Once acute illnesses present at the start of treatment have been controlled (usually in the first 1 to $2 \mathrm{mo}$ of treatment), clinical improvement becomes apparent, even in patients with limited in vitro evidence of recovery of immune function. Opportunistic infections have resolved and have not recurred, and the frequency and duration of respiratory infections and diarrhea have decreased markedly. Chronic pulmonary insufficiency, present in three older patients, has improved in two cases, but in a third it has progressed. The rate of growth improves, in some cases dramatically. Thus far, two patients 
have had uncomplicated chickenpox, after which they developed normal and persisting anti-varicella antibody titers (see below). We have also documented persisting normal anti-varicella titers in two older patients who had chickenpox while undergoing erythrocyte transfusion therapy several years before starting PEG-ADA (Rubinstein A, Chaffee S, unpublished data).

Mortality. There have been two deaths in patients undergoing treatment with PEG-ADA. A critically ill infant who was respirator-dependent died within a week of starting PEG-ADA (Souillet $\mathrm{G}$, unpublished data). The second child developed severe autoimmune hemolytic anemia after an adenovirus infection during the 2 nd month of treatment, which required immunosuppression with high-dose prednisone and azathioprine; the child did not respond and succumbed to hemolysis and Candida sepsis in the 4 th mo of treatment (Junker A, unpublished data).

\section{CASE REPORTS OF THREE PATIENTS}

Presentation. The three patients are referred to by the order in which they started treatment with PEG-ADA. PEG-ADA patient no. 5 (late onset, mild phenotype), now 10.6 y old, had no serious infections until age $3 \mathrm{y}$ and was not diagnosed until age 5. Her history and first 6 mo of PEG-ADA treatment, begun in April 1987 at age 5.8 y, have been reported (7). In January 1991, at age $9.5 \mathrm{y}$, she became the second patient enrolled in the National Institutes of Health T-cell gene transfer experiment. Her current dose of PEG-ADA is $30 \mathrm{U} / \mathrm{kg}$ once a week.

PEG-ADA patient no. 9 (delayed onset), now 5.3 y old, was diagnosed with ADA deficiency and SCID at age 2 y during an evaluation for cough of several weeks duration. She had a history of recurrent nasal congestion and cough from age $3 \mathrm{mo}$, three episodes of otitis media, and one episode of pneumonia at $1 \mathrm{y}$ of age. However, she had never been hospitalized. Treatment with PEG-ADA began in November 1988 when she was 2.2 y old. In September 1990 , at age $4.0 \mathrm{y}$, she became the first subject of experimental gene therapy. Her current dose of PEG-ADA is 26 $\mathrm{U} / \mathrm{kg}$ once a week.

PEG-ADA patient no. 14 (typical early onset, severe presentation), now 2.4 y old, was diagnosed with ADA deficiency and SCID at age $7 \mathrm{mo}$. She had a history of recurrent pneumonia, oral candidiasis, vomiting, chronic diarrhea, and failure to thrive from age 2 mo (16). She began treatment with PEG-ADA in April 1990 at age 8 mo (current dose, $30 \mathrm{U} / \mathrm{kg}$ once a week).

Correction of metabolic abnormalities. Trough plasma ADA activity in patients 5,9 , and 14 have averaged $22.4 \pm 6.7,32.9$ \pm 8.0 , and $26.7 \pm 5.8 \mathrm{nmol} / \mathrm{h} / \mathrm{mL}$, respectively. Before treatment, erythrocyte dAdo nucleotide levels were 204, 315, and 499 $\mathrm{nmol} / \mathrm{mL}$ in patients 5,9 , and 14 , respectively. With treatment, these levels have fallen to $3-9 \mathrm{nmol} / \mathrm{mL}$ (normal, $<2$ ). Erythrocyte SAHase activity in the three patients has increased from pretreatment values of $0.18-0.23 \mathrm{nmol} / \mathrm{h} / \mathrm{mg}$ protein to $>3$ $\mathrm{nmol} / \mathrm{h} / \mathrm{mg}$ (normal, $4.2 \pm 1.9 \mathrm{nmol} / \mathrm{h} / \mathrm{mg}$ ).

Immune reconstitution. Patients 9 (Fig. 1) and 14 developed a prominent thymic shadow by the 3rd mo of treatment with PEGADA. In all three patients, lymphocyte counts increased sharply during the first $6-8$ mo of treatment, then declined during the next $6-12$ mo (shown for patients 5 and 9 in Fig. $2 A$ and $B$ ). In
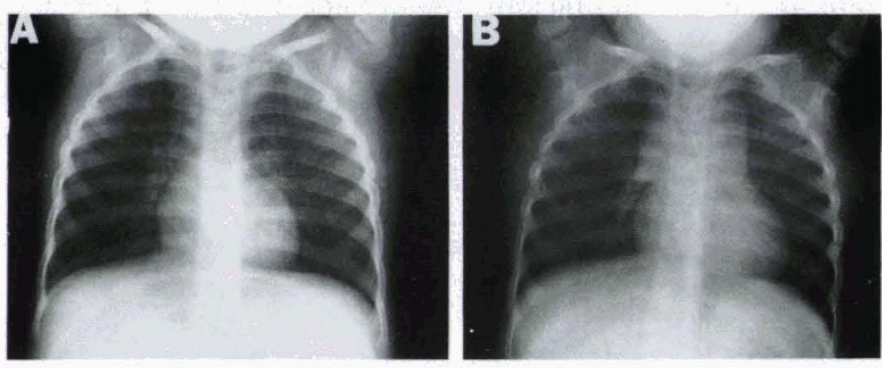

Fig. 1. Reappearance of thymus shadow on x-ray, patient 9. $A$, at diagnosis (pretreatment); $B$, at 3 mo of treatment with PEG-ADA. patient 5, $\mathrm{T}$ cells remained in a low normal range, whereas in patient 9 CD4 counts fell to 200 ; patient 14 had CD4 counts in the 400-600 range between 12 and 16 mo of treatment (not shown). In vitro lymphocyte responses to mitogens normalized by $3 \mathrm{mo}$ in patients 5 and 9 (Fig. $2 C$ and $D$ ) and by 6 mo in patient 14 (not shown) and have remained normal thereafter.

All three patients have shown significant in vitro responses to various antigens, including tetanus and Candida. In patients 5 and 9 , the in vitro lymphocyte response to streptokinase antigen was followed serially; it developed between 6 mo and 1 y of treatment and persisted through the time gene transfer studies were begun (Fig. $2 E$ and $F$ ).

All three children developed normal Ig levels and specific antibody responses while on treatment with PEG-ADA alone. At 5 mo after starting therapy, patient 5 showed a normal antibody response to immunization with $\phi$ X174, with amplification on rechallenge and IgM-to-IgG class switching (14). After immunization, she developed protective antibody titers against Haemophilus and antibody levels of $>2000 \mathrm{ng} / \mathrm{mL}$ and $678 \mathrm{ng} /$ $\mathrm{mL}$ against pneumococcal serotypes 3 and 7, respectively (antibodies to these polysaccharide antigens were undetectable before treatment). She had a normal antibody response after varicella infection, which was maintained through the time that treatments with transfected T cells began (Fig. 3). Patient 5 had antiblood group B titers of 1:8 in her 3rd y of treatment with PEGADA and of 1:512 after 7 mo of combined treatment with PEGADA and gene-transfected T cells. Patient 9 lacked isohemagglutinins at age $2 \mathrm{y}$, before treatment, but developed a normal antiA titer of 1:32 during her 1st y on PEG-ADA. After 10 mo of combined treatment, the titer had increased by two tubes to $1: 128$. As noted above, patient 9 developed autoimmune thrombocytopenia after a viral infection during her 2 nd mo of PEGADA therapy. This resolved after several months of treatment with high-dose IVIG (15). Patient 14 developed normal antibody and delayed-type hypersensitivity responses to immunization and to ordinary childhood infections during the period from 15 to $28 \mathrm{mo}$ of age ( 7 to 20 mo of PEG-ADA therapy); she has also developed normal isohemagglutinin titers (Table 1, Fig. 3).

Clinical improvement. All three patients were discharged from hospital shortly after initiation of PEG-ADA treatment and have since lived at home without medical restrictions on their social interaction. After 3 to 11 mo of PEG-ADA therapy, IVIG was discontinued in each case. In each, the frequency of respiratory infections and diarrhea decreased markedly. Growth improved in all three, most dramatically in patient 9: her weight increased from below the 10th to above the 90th percentile, and her height increased from below the 5 th to above the 25 th percentile over an 18-mo period. The clinical improvement in all three patients after starting PEG-ADA therapy was gratifying and in all cases was sustained.

Patients 5 and 14 each contracted chickenpox at 7 mo of treatment, and patient 14 also had a 48-h episode of Coxsackievirus $\mathrm{B}$ hepatitis about $1 \mathrm{y}$ after starting therapy. In each case, the illness was uncomplicated. Normal anti-varicella and antiCoxsackievirus B antibody levels appeared after these infections and have persisted (Fig. 3, Table 1). Patient 5 began school at age 6, 5 mo after starting PEG-ADA, and has attended school regularly since then (as has patient 9 since attaining school age in 1991).

\section{DISCUSSION}

Enzyme replacement with PEG-ADA has proved to be a safer and more effective way of treating ADA deficiency than red cell transfusion. Although the circulating life of $\mathrm{ADA}$ in transfused red cells is longer than that of PEG-ADA, the ADA activity of $2.5 \mathrm{~mL}$ of the clinical preparation of PEG-ADA (Adagen) is equivalent to that of $4.5 \mathrm{~L}$ of erythrocytes. Far higher levels of circulating ADA activity can therefore be maintained by weekly or biweekly intramuscular injection of PEG-ADA than by 

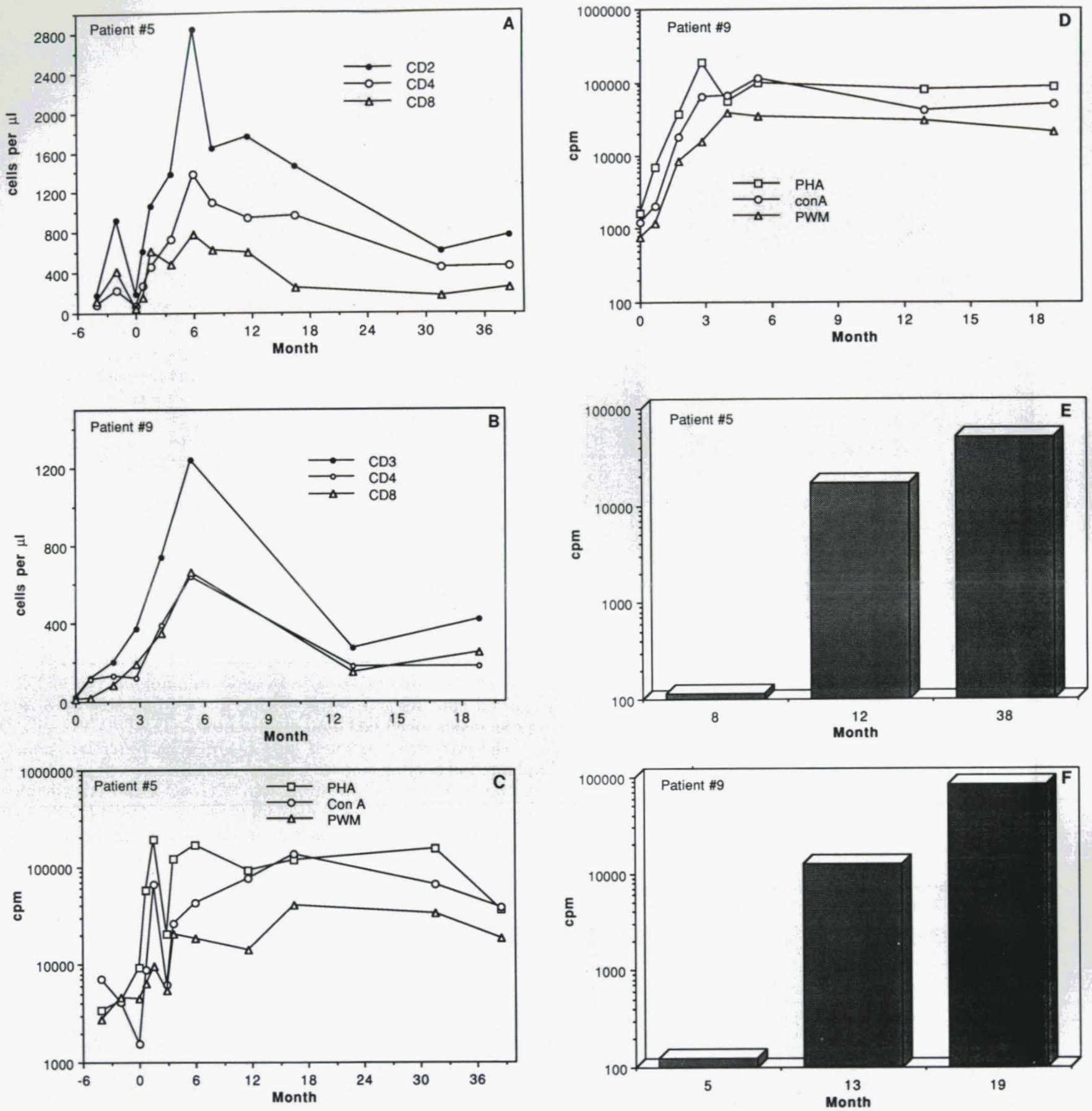

Fig. 2. Blood lymphocyte counts and lymphocyte subsets for patient $5(A)$ and patient $9(B)$. Responses of peripheral blood mononuclear cells from patient $5(C)$ and patient $9(D)$ to mitogens ( $P H A$, phytohemagglutinin; ConA, concanavalin A; $P W M$, pokeweed mitogen). Peripheral blood mononuclear cell responses to streptokinase antigen for patient $5(E)$ and patient $9(F)$.

monthly partial exchange transfusion. Our studies indicate that maintaining plasma ADA activity at 2 to 5 times greater than the normal level of total blood (erythrocyte) ADA is necessary to normalize the dATP content and SAHase activity of the ADAdeficient red cells of PEG-ADA-treated patients. Efficient elimination of $\mathrm{dAdo}$, indicated by this degree of metabolic correction, permits immature $\mathrm{T}$ cells to survive, mature, and function. Although the immune system does not become normal, treatment with PEG-ADA consistently provides a level of protective immunity sufficient to dramatically alter the natural history of ADA-deficient SCID. Indeed, for some patients who were critically ill with viral pneumonia, treatment with PEG-ADA has undoubtedly been lifesaving.
About one fifth of PEG-ADA-treated patients show very little recovery of in vitro lymphocyte function. These patients have shown the same degree of correction of metabolic abnormalities as patients with much better immune reconstitution. Some patients with limited improvement in immune function on a weekly injection schedule have now been treated with twiceweekly injections of PEG-ADA for up to $2 \mathrm{y}$. This has produced marginally better correction of metabolic abnormalities and, in some cases, an increase in lymphocyte responses to mitogens (unpublished data). Further study of these patients is in progress.

The basis for limited recovery of immune function in some PEG-ADA-treated patients remains to be determined. Very high levels of dATP (or other toxic effects of ADA deficiency) during 

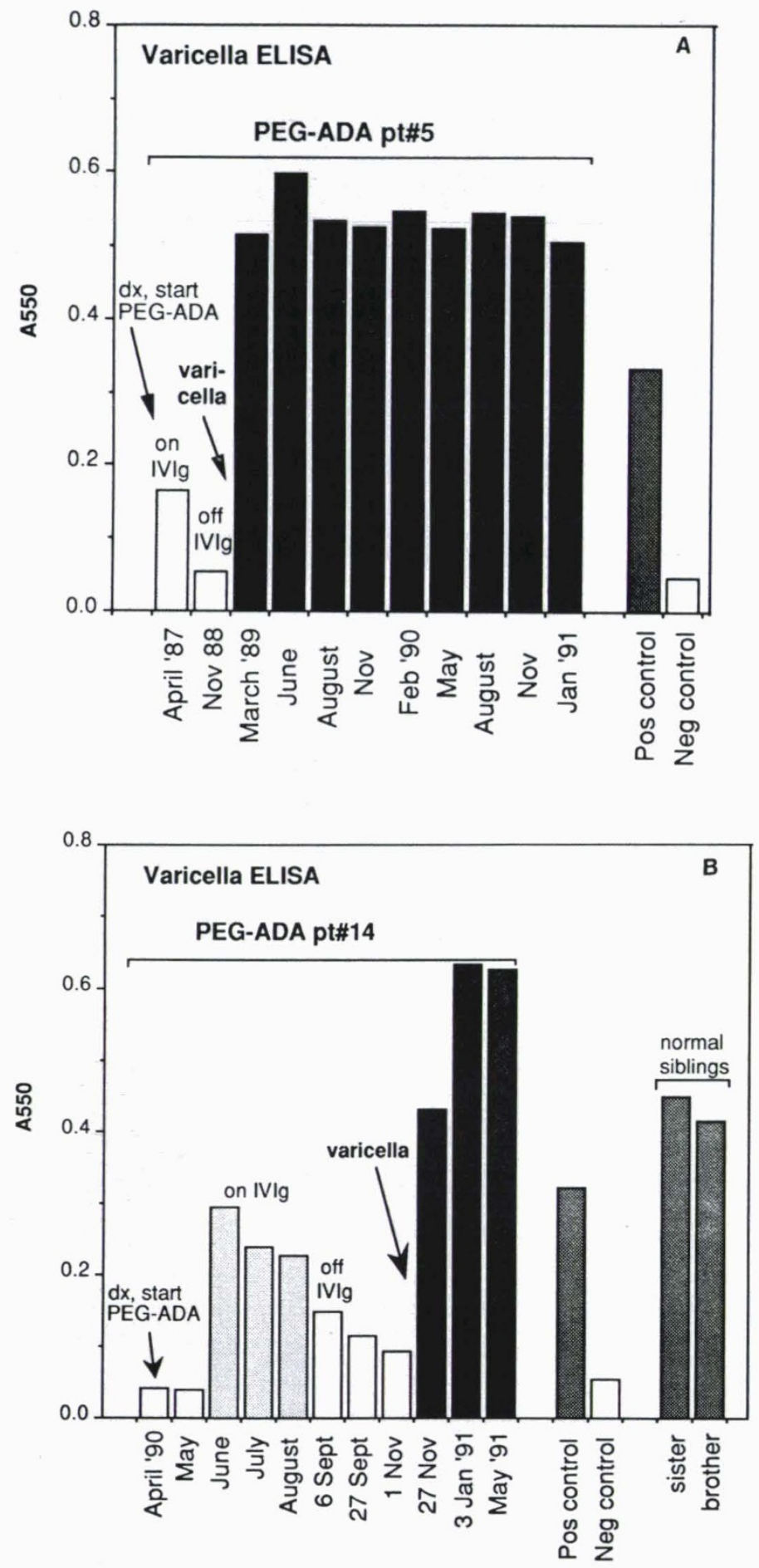

Fig. 3. Antibody response to varicella antigen after chickenpox infection for patient $5(A)$ and patient $14(B)$. Anti-varicella antibody was determined using a VARICELISA II test kit (Whittaker Bioproducts, Walkersville, MD).

fetal development may cause a degree of irreversible damage that reduces the potential for normal lymphoid differentiation by the time treatment is begun after diagnosis. As discussed by Hirschhorn (in this supplement issue), the severity of the immune deficit in untreated patients with ADA deficiency correlates with the level of erythrocyte dATP, which reflects residual total body ADA activity. This implies that specific ADA gene mutations may in part determine clinical severity and response to enzyme replacement. That this may be the case is suggested by the recent finding that one patient with a very early clinical presentation
Table 1. Summary of immune responses of PEG-ADA patient 14

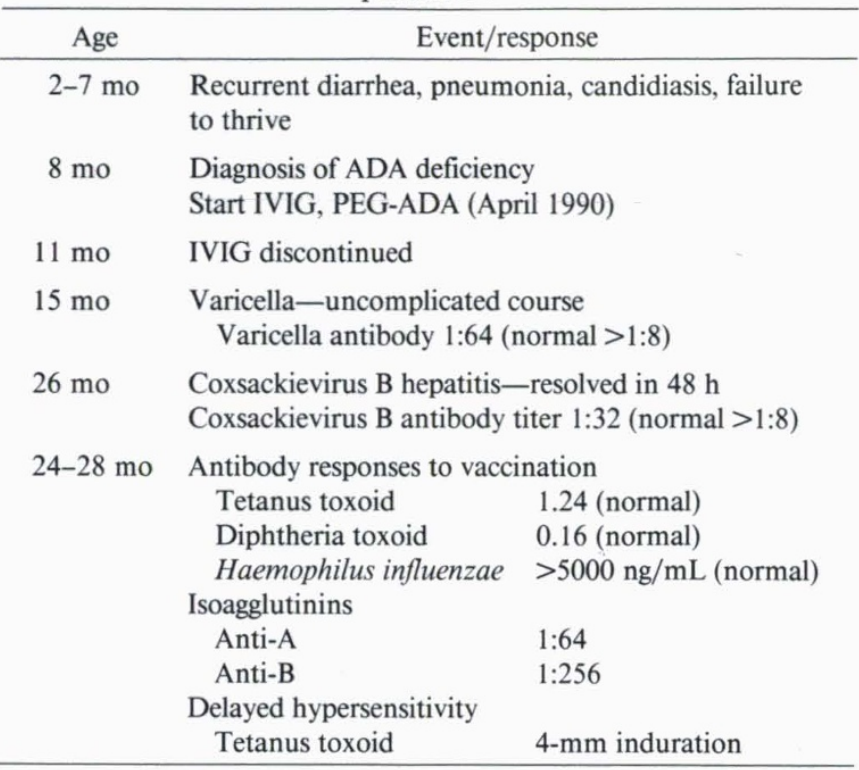

and limited response to PEG-ADA is homozygous for an $\operatorname{Arg}_{216}>$ Gly substitution (17). However, as reviewed by Hirschhorn, many point mutations have been shown to cause ADA deficiency and most patients are compound heterozygotes. A large number of patients will therefore have to be studied to establish the relationship between genotype and phenotype. To this end, we are analyzing ADA gene mutations in PEG-ADAtreated patients and characterizing the residual activity of the products of subcloned mutant enzymes.

The preferred treatment for ADA deficiency remains transplantation of bone marrow from an HLA-identical sibling. When a matched donor is not available, PEG-ADA and HLA-haploidentical bone marrow transplantation are potentially effective but probably incompatible alternatives (improving recipient immune function with PEG-ADA might enhance the chances of graft rejection). Some immunologists feel that haploidentical transplantation should always be performed before resorting to enzyme replacement, because the procedure is potentially curative. However, only the first of 29 patients had undergone unsuccessful haploidentical bone marrow transplantation before receiving PEG-ADA. The reasons for choosing PEG-ADA as primary therapy have varied, but a major factor has been the significant morbidity and mortality of haploidentical transplantation, particularly when carried out using preconditioning with cytotoxic drugs $(18,19)$. A 1990 review of the European experience reported a 2-y posttransplant survival rate of $53 \%$ in 19 ADA-deficient SCID patients treated with haploidentical marrow (19). In contrast, only two deaths have occurred among PEGADA-treated patients. The difference in mortality is more impressive when it is appreciated that several PEG-ADA-treated patients had severe viral or Pneumocystis carinii pneumonia and were considered too ill to undergo marrow transplantation. There have been no clinically significant adverse reactions to PEGADA, whereas graft versus host disease is potentially a serious complication of bone marrow transplantation.

A form of gene therapy is currently under investigation at the National Institutes of Health (reviewed by Blaese in this issue). The gene treatment involves repeated infusions of activated, IL2-dependent patient $\mathrm{T}$ cells that have been exposed in vitro to an ADA cDNA-bearing retroviral vector. PEG-ADA therapy is required to provide sufficient mature patient $\mathrm{T}$ cells for gene transfer to be performed. Whether, after repeated cycles, the level of circulating ADA activity provided by infusion of gene-transfected $T$ cells will be sufficient to sustain the survival and function of the patient's ADA-deficient T cells in the absence of ongoing 
PEG-ADA therapy remains to be determined $(2.5 \mathrm{~mL}$ of PEGADA has as much ADA activity as $10^{12}$ normal T cells).

Thus far, two ADA-deficient patients (PEG-ADA patients 5 and 9 described above) have been enrolled in the gene therapy study. Before entering the study, they had been treated with PEG-ADA for almost 2 and 4 y, respectively, and they have continued to receive weekly injections of PEG-ADA. Patient 5 had a late onset and patient 9 a delayed onset of immunodeficiency, clinical phenotypes associated with a good response to enzyme replacement [including red cell transfusion therapy (12)]. Indeed, as described above, both of these patients, and a third child presented to illustrate a more typical early-onset SCID phenotype, had recovered significant specific and protective immune function on PEG-ADA alone. They had been able to discontinue treatment with IVIG and prophylactic antibiotics and were considered by their physicians to have had excellent clinical responses to PEG-ADA. Given the sustained clinical improvement of these children on enzyme replacement alone, judgment regarding any additional benefit of gene therapy must be reserved until PEG-ADA is discontinued.

PEG-ADA is truly an orphan drug. It is lifesaving but very expensive, and it is not curative. Moreover, the long-term outcome of therapy remains to be defined. It is to be hoped that the patients now receiving PEG-ADA will one day be cured by undergoing stem cell gene therapy or possibly a form of bone marrow transplantation. However, based on the experience to date, we are optimistic that children receiving PEG-ADA will be able to lead reasonably healthy, active lives until those procedures are developed and can be applied in a safe, reliable, and effective manner.

Acknowledgments. The authors appreciate discussions with the following collaborators who have contributed samples and information about the immune function and clinical status of patients under treatment with PEG-ADA: M. Ballow, J. Bastian, M. Berger, C. Bordignon, C. Bory, R. Buckley, S. Douglas, J. ElDahr, A. Fischer, D. Girault, B. Hillman, D. Hummell, A. Junker, A. Kobayashi, R. Kobayashi, A. Lawton, G. Marshall, D. Matheson, C. Roifman, A. Rubinstein, Y. Sakiyama, R. Schiff, C. Schlossman, G. Souillet, D. Umetsu, D. Wara, and K. Weinberg.

\section{REFERENCES}

1. Hershfield MS, Buckley RH, Greenberg ML, Melton AL, Schiff R, Hatem C, Kurtzberg J, Markert ML, Kobayashi RH, Kobayashi AL, Abuchowski A 1987 Treatment of adenosine deaminase deficiency with polyethylene glycolmodified adenosine deaminase. N Engl J Med 316:589-596

2. Abuchowski A, McCoy JR, Palczuk NC, van Es T, Davis FF 1977 Effect of attachment of polyethylene glycol on immunogenicity and circulating life of bovine liver catalase. J Biol Chem 252:3582-3586

3. Abuchowski A, van Es T, Palczuk NC, Davis FF 1977 Alteration of immunological properties of bovine serum albumin by covalent attachment of polyethylene glycol. J Biol Chem 252:3578-3581

4. Davis S, Abuchowski A, Park YK, Davis FF 1981 Alteration of the circulating life and antigenic properties of bovine adenosine deaminase in mice by attachment of polyethylene glycol. Clin Exp Immunol 46:649-652

5. Kredich NM, Hershfield MS 1989 Immunodeficiency diseases caused by adenosine deaminase deficiency and purine nucleoside phosphorylase deficiency. In: Scriver CR, Beaudet AL, Sly WS, Valle D (eds) The Metabolic Basis of Inherited Disease, 6th Ed. McGraw-Hill, New York, pp 1045-1075

6. Hershfield MS, Chaffee S 1991 PEG-enzyme replacement therapy for adenosine deaminase deficiency. In: Desnick RJ (ed) Treatment of Genetic Diseases. Churchill Livingstone, New York, pp 169-182

7. Levy Y, Hershfield MS, Fernandez-Mejia C, Polmar SH, Scudiery D, Berger M, Sorensen RU 1988 Adenosine deaminase deficiency with late onset of recurrent infections: response to treatment with polyethylene glycol-modified adenosine deaminase (PEG-ADA). J Pediatr 113:312-317

8. Bory C, Boulieu R, Souillet G, Chantin C, Rolland MO, Mathieu M, Hershfield MS 1990 Comparison of red cell transfusion and polyethylene glycol-modified adenosine deaminase therapy in an adenosine deaminase-deficient child. Pediatr Res 28:127-130

9. Girault D, Le Deist F, Debré M, Pérignon JL, Herbelin C, Griscelli C, Scudiery D, Hershfield M, Fischer A 1992 Traitement du deficit en adenosine desaminase par l'adenosine desaminase couplee au polyethylene glycol (PEGADA). Arch Fr Pediatr 49:339-343

10. Chaffee S, Mary A, Stiehm ER, Girault D, Fischer A, Hershfield MS 1992 IgG antibody response to polyethylene glycol-modified adenosine deaminase
(PEG-ADA) in patients with adenosine deaminase deficiency. $\mathrm{J}$ Clin Invest 89:1643 - 165

11. Polmar SH, Stern RC, Schwartz AL, Wetzler EM, Chase PA, Hirschhorn R 1976 Enzyme replacement therapy for adenosine deaminase deficiency and severe combined immunodeficiency. N Engl J Med 295:1337-1343

12. Polmar SH 1980 Metabolic aspects of immunodeficiency disease. Semin Hem atol 17:30-43

13. Lee N, Kobayashi RH, Chaffee S, Hershfield MS, Stiehm ER 1990 Suppression of an inhibitory antibody to bovine adenosine-deaminase (ADA) and improved cellular immunity following intravenous immunoglobulin and polyethylene-glycol (PEG-ADA). Pediatr Res 27:155A(abstr)

14. Ochs HD, Buckley RH, Kobayashi RH, Kobayashi AL, Sorensen RU, Douglas SD, Hamilton BL, Hershfield MS 1992 Antibody responses to bacteriophage $\phi \mathrm{X} 174$ in patients with adenosine deaminase deficiency. Blood 80:11631171

15. Sorensen RU, Berger M, Hershfield MS 1990 Self-limited thrombocytopenia in a patient treated with polyethylene glycol (PEG) modified adenosine deaminase. Pediatr Res 27:162A(abstr)

16. Lahood NN, Hershfield MS, Leiva LE, Sorensen RU 1991 Recurrent infection, chronic diarrhea, and failure to thrive in a 6 month old infant. Ann Allergy 67:389-393

17. Hirschhorn R, Chakravarti V, Puck J, Douglas SD 199I Homozygosity for newly identified missense mutation in a patient with very severe combined immunodeficiency due to adenosine deaminase deficiency (ADA-SCID). Am J Hum Genet 49:878-885

18. O'Reilly RJ, Keever CA, Small TN, Brochstein J 1989 The use of HLA-nonidentical T-cell-depleted marrow transplants for correction of severe combined immunodeficiency disease. Immunodefic Rev 1:273-309

19. Fischer A, Landais P, Friedrich W, Morgan G, Gerritsen B, Fasth A, Porta F, Griscelli C, Goldman SF, Levinsky R, Vossen J 1990 European experience of bone marrow transplantation for severe combined immunodeficiency. Lancet 336:850-854

\section{FLOOR DISCUSSION}

Dr. Hirschhorn: I was fascinated by the two sisters you described, and I wonder if they were an example of epistasis, which I discussed. It is something I never understood until now. Is it possible that there is a genetic variation between either the ability to phosphorylate the dAdo or to degrade dAdo, and have you looked at whether there are differences between the two sisters?

Dr. Hershfield: No, we are setting up cell lines on them now and we are beginning to look at the mutations. We would like to express each allele from the two children. Another possibility is that there might be a difference in the ability of the sisters to excrete dAdo.

Dr. Hirschhorn: That is epistasis, too. The term epistasis covers the ball park.

Dr. Hershfield: Most of the dAdo that is formed in these children is excreted. So it would take a relatively small difference in excretion to change the dATP accumulation significantly, and they certainly differ in their ability to accumulate dATP in their red cells.

Dr. Hirschhorn: One other comment: the appearance of specific antibody responses in patients is very striking in comparing the results of the PEG-ADA with the best of the results of the partial exchange transfusions. In other words, you saw the clinical well-being, the growth curve, etc., but the appearance of the specific antibody and the appearance of normal lymphocyte counts is very striking. With respect to that, what I find fascinating is the very small difference in terms of metabolic correction. I know you showed metabolic corrections with ranges of about 150 after red cell transfusions, but after the kinds of really vigorous partial exchange transfusions every $2 \mathrm{wk}$, the difference in values (and here I am talking about values in patients where I have done both, your patients with PEG-ADA and the same patients on red cell transfusions) is very small, and it suggests that there is really a very critical point for toxicity.

Dr. Hershfield: That may be true, but one problem with doing dATP levels on people who have been transfused recently is that you are looking at a mixture of cells, some with ADA activity in them. So I think those cells have no dATP.

Dr. Hirschhorn: But if we do the same thing with the dAdo excretion. .

Dr. Hershfield: We have not looked at dAdo excretion.

Dr. Hirschhorn: Well, usually the two are very closely related. 
I think that one of the differences may be very small. There may be a very fine line.

Dr. Hershfield: There may be, but I would still say, without belaboring it, that in the children who have had minimal recovery of antigen-specific responses and gone on to two injections a week we see a little bit greater decrease in dATP; it is a significant decrease to very, very low levels, and yet they do not develop antigen-specific responses.

Dr. Gelfand: Unfortunately, we will have to conclude this discussion now. An important part of any discussion on this topic is the cost of PEG-ADA and how one might select patients for whom it is appropriate. 